\title{
Vigencia de una experiencia para la prevención de infección
}

\author{
Nérida Rodríguez Oliva \\ Máster en Salud Pública. Especialista I Grado en Epidemiología. Cardiocentro \\ "Ernesto Che Guevara". Santa Clara, Villa Clara, Cuba.
}

Hace varios años se presentó un brote de infección nosocomial (bacteriemia severa a Serratia marcescens) en una sala de cuidados intermedios quirúrgicos que afectó a 21 casos con 7 fallecidos para una letalidad de 33,3\%. Fueron mis primeros años de epidemióloga y aún recuerdo perfectamente la presión que tuve por el personal asistencial; primeramente cambiando los pacientes de sala y fumigándola, formalizando el salón de operaciones, entre otras, y el Departamento de Epidemiología imponiendo barreras; lavado de manos, secado con servilletas estériles, aplicando en general medidas de asepsia y antisepsia, pero siempre manteniendo el ojo visor porque existía una situación con las ámpulas de dextrosa al $5 \%$ y clorosodio al $0,9 \%$ para diluir medicamentos, dado por rotura en la fabrica. Por tal motivo eran utilizados los frascos de cristal de dextrosa al $5 \%$ y clorosodio al 0,9\% ambos de 1000 mililitros obteniendo de ellos a través de punciones la cantidad necesaria para diluir los medicamentos.

La urgencia que conlleva realizar procederes en un caso operado, descuidos de las medidas para destapar y puncionar los frascos, la repunciones posteriores, la violación del lavado de manos y el tiempo de 24 horas para el uso de dichos frascos, proporcionó la vía para la transmisión del agente responsable. Se logró aislar en uno de los frascos de dextrosa al $5 \%$ examinado por el laboratorio de microbiología la Serratia marcescens con un bloque de resistencia igual al de las cepas aisladas de los casos infectados, considerándose como agente responsable del brote y hallada la vía de transmisión. La única satisfacción que quedó de este brote fue precisamente encontrar la fuente de infección, por lo cual obtuve un premio en un Simposio Nacional por la investigación realizada.

Esta experiencia condicionó la orientación para el uso de frascos de $1000 \mathrm{~mL}$ o de $500 \mathrm{~mL}$ de dextrosa al $5 \%$ o clorosodio al 0,9 \% para diluir para lo cual se deben seguirse las siguientes precauciones: 
1. Limpiar el frasco por fuera y secar.

2. Lavado de manos higiénico para efectuar el proceder.

3. Abrir la retapa metálica con pinzas.

4. Aplicar alcohol yodado a la tapa de goma.

5. Utilizar aguja número 18 estériles para provocar la perforación.

6. Extraer en jeringuilla la cantidad de líquido necesaria para la dilución.

7. Dejar cubriendo con gasa estéril la tapa y aguja.

8. Identificar el frasco con la fecha y hora de apertura.

9. Desechar el frasco en uso de 8 a 12 horas de abierto.

En caso de los nuevos frascos de dextrosa o clorosodio fabricados de material termo sensibles (bolsas) se recomienda lo siguiente:

1. Limpiar el frasco por fuera y secar.

2. Lavado de manos higiénico para efectuar el proceder.

3. Desinfectar el extremo donde se insertan los equipos de infusión para efectuar la punción con aguja directa a las jeringuillas.

4. Aplicar gasa estéril en la región de la bolsa puncionada.

5. Mantener en posición vertical la bolsa, se sugiere dejar dentro de una cubeta tapada

o caja para evitar salida de liquido.

6. Identificar el frasco con la fecha y hora de apertura.

7. Desechar el frasco (bolsa) en uso de 8 a $12 \mathrm{~h}$ de abierto.

Rememorar estas deficiencias nutre la búsqueda constante de medidas para la prevención de infecciones, especialmente en países con recursos limitados. ${ }^{1-7}$

\section{REFERENCI AS BI BLI OGRAFI CAS}

1. Maki D G, McCormack K N. Defatting catheter insertion sites in total parenteral nutrition is of no value as an infection control measure. Am J Med. 1987; 83:83340. 
2. Bert F. Risk factors and treatment of methicillin-resistant Staphylococcus aureus infections. Presse Med 2002;31(3):1792-6.

3. Centers for Disease Control and Prevention. Guidelines for the prevention of intravascular catheter-related infection. MMWR. 2002;51RR-10:1-36.

4. Brooks GF, Batel JS, Morse SA. Microbiologia Médica de Jawetz, Melnick y Adelberg. $17^{\text {a }}$ ed. Mexico: Ed. Manual Moderno; 2006.

5. Dotres C, Ramirez A, Santi M. Actualización del Programa de Prevención y Control de Infección Intrahospitalaria. La Habana: MINSAP,Dirección Nacional de Epidemiología; 1996.

6. Haddy RI, Mann BL, Nadkami D. Nosocomial Serratia marcescens infections associated with extrinsic contamination of a liquid nonmedicated soap. Infect Control Hosp Epidemiol. 2000; 21(3):196-9.

7. Yu WL, Lin CW, Wang DY. Serratia marcescens bacteremia: clinical features and antimicrobial susceptibilities of the isolates. J Microbiol Inmunol Infect. 1998; 31(3): 171-9.

Recibido: 18 de septiembre de 2008.

Aprobado: 28 de octubre de 2008.

Nérida Rodríguez Oliva. Cardiocentro "Ernesto Che Guevara". Santa Clara, Villa Clara, Cuba.

E-mail: neroli@cardiovc.sld.cu 